\title{
Strategische motieven voor het splitsen van concerns
}

Prof. Dr. S.W. Douma en Dr. A.A.C.J. van Oijen

\section{Inlciding}

Dit artikel probeert een antwoord te geven op de vraag in welke situaties het splitsen van een concern voordelen oplevert. Onder een concern verstaan wij een onderneming bestaande uit meerdere business units die worden aangestuurd door een hoofdkantoor. Wij gaan ervan uit dat het concern een $\mathrm{NV}$ is waarvan de aandelen in handen zijn van een groot aantal aandeelhouders. Deze NV bezit verschillende werkmaatschappijen (de business units).

Wat wij onder het splitsen van een concern verstaan is aangegeven in figuur 1 . Voor de splitsing is er één houdstermaatschappij (I) die eigenaar is van een aantal business units. $\mathrm{Na}$ de splitsing zijn er twee houdstermaatschappijen; sommige werkmaatschappijen behoren tot houdstermaatschappij la, andere tot houdstermaatschappij II. De twee houdstermaatschappijen hebben direct na de splitsing dezelfde aandeelhouders. Een dergelijke splitsing kan worden geëffectueerd door bij notariële akte houdstermaatschappij I te splitsen, waarbij de aandeelhouders van I voor ieder aandeel I dat zij bezitten een aandeel II ontvangen. Vaak zal I tegelijkertijd haar naam wijzigen in la.

Splitsen is dus niet hetzelfde als verkoop van een of enkele business units aan derden, bijvoorbeeld aan het management van die business units (door middel van een MBO), aan beleggers of aan een andere onderneming.

Prof. Dr. S.W. Douma en Dr. A.A.C.J. van Oijen zijn beide werkzaam bij het Departement Organisatie en Strategie van de Katholieke Universiteit Brabant, Tilburg.
Eén mogelijk voordeel van het splitsen van een concern is de grotere doorzichtigheid die dit oplevert voor beleggers. Dat zou kunnen leiden tot een hogere waardering op de vermogensmarkt. Aldus zou splitsen voordelen kunnen opleveren voor de aandeelhouders. Deze redenering berust op de veronderstelling dat de vermogensmarkt niet efficiënt is (beleggers zijn niet in staat een multibusiness-onderneming goed te waarderen). Dit motief komt aan de orde in de bijdrage van Moerland elders in dit nummer. Wij beperken ons tot reële voordelen, voordelen die ertoe leiden dat de twee delen waarin een concern zich splitst betere operationele resultaten behalen dan het ongesplitste concern.

In dit artikel gaat het dus on de vraag in welke situaties zulke reële voordelen van splitsing kunnen optreden. Het is niet eenvoudig die vraag te beantwoorden. Een eerste voorlopig antwoord is: door middel van splitsing wordt een te ver doorgeschoten diversificatie teruggedraaid. Dat antwoord berust op de veronderstelling dat er zoiets als een optimale diversificatiegraad bestaat. Een zekere mate van diversificatie leidt tot betere prestaties, maar als de diversificatiegraad een bepaalde grens overschrijdt leidt dat tot minder goede prestaties. Door splitsing ontstaan twee concerns die ieder voor zich minder sterk gediversifieerd zijn en die dus beter zullen presteren. Dat antwoord is echter niet geheel bevredigend: wat is dan de optimale diversificatiegraad? Is die optimale diversificatiegraad voor alle concerns dezelfde of zijn er verschillen tussen concerns? Een zeer uitgebreid onderzoek naar het verband tussen diversificatiegraad en prestaties heeft nog niet tot een eenduidige conclusie geleid (Ramanujam en Varadarajan, 1989). Het lijkt aannemelijk 
Aandeelhouders:

Hoofdkantoor:

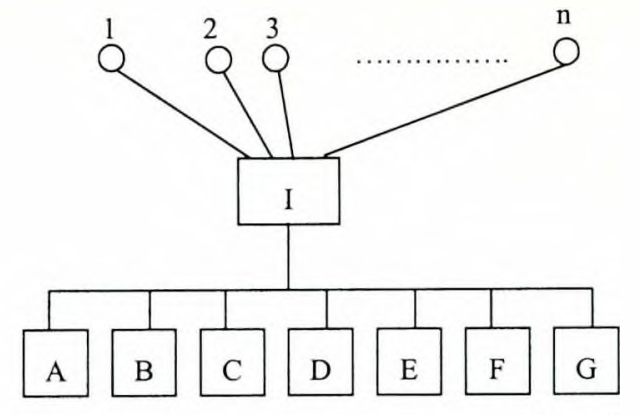

Situatie vóór de splitsing

Aandeelhouders:

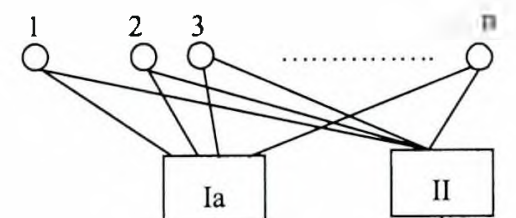

Hoofdkantoren:

Business units:

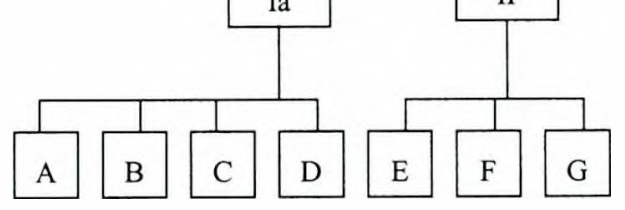

Situatie onmiddellijk na de splitsing

Figuur 1: Het splitsen van een concern

dat gediversifieerde concerns goede prestaties kunnen boeken mits ze een besturingsstijl toepassen die aansluit op de gevolgde strategie. Daarom moet bij het verklaren van het succes van een concernverband niet alleen de mate van diversificatie, maar ook de besturing door het hoofdkantoor worden betrokken (Van Oijen, 1997). Het lijkt aannemelijk dat de optimale diversificatiegraad samenhangt met de gekozen besturingsstijl. Ook een beschouwing over de voordelen van splitsing moet beginnen met het identificeren van die situaties waarin een concernverband meer nadelen dan voordelen biedt. Daarbij spelen de door het concern gehanteerde besturingsstijl en de kenmerken van de portfolio een doorslaggevende rol. De besturingsstijl moet passen bij de kenmerken van de portfolio. Als het niet mogelijk is de besturingsstijl af te stemmen op de kenmerken van de portfolio, is splitsing van het concern geboden. Het tweede antwoord is dus dat splitsing van een concern voordelen biedt in die situaties waarin een goede fit tussen besturingsstijl en kenmerken van de portfolio niet kan worden bereikt.
Dit artikel is verder als volgt opgebouwd. We beginnen met een beschouwing over de besturingsstijlen die een concern kan toepassen (paragraaf 2). Vervolgens bespreken wij welke kenmerken van de portfolio van belang zijn (paragraaf 3 ) en de fit tussen de besturingsstijl en de kenmerken van de portfolio (paragraaf 4). Daarbij zal blijken dat het niet in alle gevallen mogelijk is om de besturingsstijl af te stemmen op de portfolio. In die gevallen is splitsing van het concern geboden. Dan volgt, in paragraaf 5 , een korte beschouwing over de samenhang tussen de besturingsstijl en de optimale diversificatiegraad. In situaties waarin de optimale diversificatiegraad is overschreden, kan splitsing van het concern een oplossing bieden. In paragraaf 6 worden ter illustratie twee praktijkvoorbeelden besproken. Paragraaf 7 bevat enkele slotopmerkingen.

\section{Besturingsstijl}

Het hoofdkantoor van een concern kan kiezen uit twee verschillende besturingsstijlen: een stijl van strategische besturing en een stijl van finan- 
ciële besturing. Die twee stijlen verschillen op de volgende punten van elkaar.

I Betrokkenheid ran het hoofdkantoor bij het opstellen van de strategie voor de business unit. Goold en Campbell (1987) hebben gevonden dat die betrokkenheid in de praktijk sterk uiteenloopt. In het ene uiterste (de strategische besturingsstijl) is het hoofdkantoor nauw betrokken bij het opstellen van de strategie van de business unit en keurt het die strategie ook expliciet goed. In het andere uiterste (de financiële besturingsstijl) ontwikkelt de business unit zijn strategie geheel zelfstandig; het hoofdkantoor bekijkt de strategie niet eens.

2 Invloed van het hoof dkantoor bij benoemingen in de business units. Bij een strategische besturingsstijl bemoeit het hoofdkantoor zich niet alleen met het benoemen van directeuren van de business units, maar ook met het benoemen van anderen. zoals managers van het tweede echelon van de business units. Bij een financiële besturingsstijl bemoeit het hoofdkantoor zich alleen met het benoemen van de directeur van de business unit.

3 Inzet van instrumenten voor het onderling op elkaar afstemmen van husiness units. Bij een strategische besturingsstijl probeert het hoofdkantoor business units onderling op elkaar af te stemmen door gebruik te maken van bepaalde instrumenten. Voorbeelden daarvan zijn het instellen van projectgroepen met leden afkomstig uit verschillende business units en het standaardiseren van bepaalde bedrijfsprocessen (waaronder inrichting van de bestuurlijke informatieverwerking en -automatisering).

4 Verlenen van diensten. Bij een strategische besturingsstijl verleent het hoofdkantoor gewoonlijk een reeks van diensten aan de business units. Voorbeelden zijn centrale afdelingen voor research en development, logistiek en milieumanagement.

5 Beoordelen van prestaties. Bij een financiële besturingsstijl legt het hoofdkantoor bij het beoordelen van prestaties van business-unitmanagers heel veel nadruk op het bereiken van financiële doelstellingen. Het budget is "heilig"; managers die hun budget niet halen worden daar op 'afgerekend". De managers van de business unit ontvangen een forse bonus als zij hun budget wel halen. Bij een strategische besturingsstijl worden managers niet uitsluitend beoordeeld aan de hand van financiële criteria. Ook andere criteria spelen een rol. Voorbeelden zijn ontwikkeling van het marktaandeel. voortgang van productontwikkeling, oordeel van consumenten over kwaliteit van producten en dienstverlening, ontwikkeling van 'human resources' en bijdragen aan samenwerking met andere business units.

6 Bonussen voor business-unitmanagers. Bij een financiële besturingsstijl maken bonussen een groot deel uit van de totale beloning van business-unitmanagers. De bonus is direct gekoppeld aan de financiële resultaten van de eigen business unit. Ook bij een strategische besturingsstijl kunnen business-unitmanagers een bonus ontvangen. Deze bonus maakt echter een kleiner deel van de totale beloning uit en is eerder gekoppeld aan de financiële resultaten van het concern als geheel dan aan de financiële resultaten van de eigen business unit.

Bij een strategische besturingsstijl probeert het hoofdkantoor vooral samenwerking tussen de business units te bevorderen. Hill ( 1994) spreekt daarom van een coöperatieve besturingsstijl. Bij een financiële besturingsstijl probeert het hoofdkantoor individuele business-unitmanagers tot maximale prestaties te brengen. Daardoor ontstaat er eerder een sfeer van onderlinge rivaliteit dan van samenwerking. De business units concurreren bijvoorbeeld om toewijzing van middelen door het hoofdkantoor aan hun investeringsvoorstellen. Hill (1994) duidt deze besturingsstijl dan ook aan als een competitieve besturingsstijl. Er is dus sprake van twee fundamenteel verschillende besturingsfilosofieën. De verschillen zijn samengevat in tabel 1 . Het belangrijkste verschil is dat in een strategische (of coöperatieve) besturingsstijl het hoofdkantoor allereerst samenwerking tussen de business units wil bevorderen. Dat leidt echter onvermijdelijk tot 'performance ambiguities": het wordt minder duidelijk wie waarvoor verantwoordelijk kan worden gesteld. Individuele prestatieprikkels zijn relatief zwak. Bij een financiële besturingsstijl spelen individuele prestatieprikkels een allesoverheersende rol.

De managementfilosofieën waarop deze twee besturingsstijlen berusten zijn zo verschillend dat één hoofdkantoor onmogelijk beide stijlen tegelijkertijd kan toepassen. Die mening wordt door meerdere auteurs gedeeld (Hill, 1988 en 
Tabel 1: Samenvatting van de twee besturingsstijlen

\begin{tabular}{|c|c|c|}
\hline Besturingsstijl & Strategisch & Financieel \\
\hline Formuleren van business unit-strategie & $\mathrm{BU}$-manager in overleg met $\mathrm{HK}$ & BU-manager \\
\hline Centralisatie van sommige functies? & $\mathrm{Ja}$ & Nee \\
\hline Benoemingen door $\mathrm{HK}$ & $\begin{array}{l}\text { Niet alleen BU-manager, } \\
\text { HK ook betrokken bij benoemen } \\
\text { andere (functionele) managers }\end{array}$ & Alleen BU-manager \\
\hline Beoordelen prestaties van BU-manager & $\begin{array}{l}\text { Mix van deels kwalitatieve } \\
\text { strategische criteria en } \\
\text { financiële criteria }\end{array}$ & Alleen financiële criteria \\
\hline Bonus van BU-manager & $\begin{array}{l}\text { Bescheiden; gekoppeld aan } \\
\text { prestaties concern als geheel }\end{array}$ & $\begin{array}{l}\text { Groot deel van totale beloning; } \\
\text { gekoppeld aan financiële } \\
\text { resultaten van eigen BU }\end{array}$ \\
\hline Omvang HK & Groot & Klein \\
\hline
\end{tabular}

1994: Hoskisson, 1987: Hill en Hoskisson, 1987). leder hoofdkantoor moet dus een keuze maken: ofwel kiezen voor een strategische, op onderlinge samenwerking gerichte besturingsstijl ofwel kiezen voor een financiële, op onderlinge competitie gerichte, besturingsstijl.

Natuurlijk zijn de twee beschreven stijlen uitersten, die vooral ter wille van de duidelijkheid zo tegenover elkaar zijn gezet. In de praktijk zal men veel tussenvormen tegenkomen'. Dat laat echter onverlet dat het hoofdkantoor één besturingsstijl (zij het wellicht een tussenvorm in plaats van een van de twee beschreven uitersten) moet kiezen. Wij gaan er dus van uit dat het hoofdkantoor niet ten opzichte van sommige business units de ene en ten opzichte van andere business units een geheel andere besturingsstijl kan hanteren.

\section{Kenmerken van de portfolio}

Het hoofdkantoor van een concern kan per saldo alleen waarde toevoegen als er sprake is van een goede fit tussen de besturingsstijl en de kenmerken van de portfolio. Daarbij zijn twee kenmerken van belang: de mate van verwantschap tussen de business units en de 'time frame' of 'tijdshorizon' van de business units.
De mate van verwantschap tussen de business units bepaalt in hoeverre er mogelijkheden zijn voor het behalen van synergievoordelen. Synergievoordelen kunnen optreden als de portfolio zodanig is samengesteld dat er sprake kan zijn van:

- onderlinge leveringen tussen business units;

- gemeenschappelijk gebruik van faciliteiten of van hulpbronnen door verschillende business units;

- het uitwisselen van knowhow en/of het overdragen van ervaring tussen de business units.

Synergievoordelen kunnen dus alleen optreden als er tussen de business units een zekere mate van verwantschap bestaat. Alleen als er sprake is van verwantschap zijn er mogelijkheden om te profiteren van het gemeenschappelijk gebruik van een researchlaboratorium (Philips, DSM), het hanteren van een gemeenschappelijke merknaam (Philips, Heineken), het uitwisselen van knowhow en het overdragen van ervaring (Ahold, Heineken) of van onderlinge leveringen (DSM). Indien de potentiële synergievoordelen daadwerkelijk worden gerealiseerd zal dat leiden tot lagere kosten bij de business units en/of tot meer productdifferentiatie, waardoor hogere opbrengstprijzen kunnen worden gerealiseerd. 
Om synergievoordelen te realiseren moet het hoofdkantoor een strategische besturingsstijl toepassen. Door betrokken te zijn bij het formuleren van de strategische plannen van de business units, door invloed uit te oefenen op benoemingen van managers van het tweede echelon van de business units, door het instellen van projectgroepen met mensen van verschillende business units en door bij het beoordelen van prestaties van managers van business units niet alleen te letten op financiële prestaties wordt samenwerking tussen business units sterk bevorderd. Het gebruik van een strategische besturingsstijl brengt echter relatief hoge kosten met zich mee. Doordat het hoofdkantoor bij gebruik van een strategische besturingsstijl veel meer activiteiten verricht dan bij gebruik van een financiële besturingsstijl, moet het hoofdkantoor groter zijn. Behalve de kosten van het hoofdkantoor zijn er ook minder goed meetbare kosten verbonden aan het gebruik van een strategische besturingsstijl. Daarbij valt te denken aan de kosten die in de business units moeten worden gemaakt om aan de informatievraag van het hoofdkantoor te voldoen. Bij gebruik van een strategische besturingsstijl zijn ook die minder goed zichtbare kosten hoger dan bij gebruik van een lïnanciële besturingsstijl.

Als er geen sprake is van onderlinge leveringen en er ook geen mogelijkheden zijn voor het gemeenschappelijk gebruik van faciliteiten of het uitwisselen van knowhow, kan het hoofdkantoor het beste een financiële besturingsstijl toepassen. Door het toepassen van een financiële besturingsstijl geeft het hoofdkantoor aan de managers van de business units maximale prestatieprikkels. Bovendien zijn de kosten van het hoofdkantoor laag, omdat met een zeer klein hoofdkantoor kan worden volstaan. Omdat de informatiebehoefte van het hoofdkantoor gering is, behoeven de business units ook weinig kosten te maken om aan die informatievraag te voldoen.

De besturingsstijl moet niet alleen passen bij de mate van verwantschap tussen de business units, maar ook bij de aard van de individuele business units. Daarbij moet vooral worden gedacht aan het verschil tussen business units met een lange en een korte tijdshorizon. Bij een business unit met een lange tijdshorizon hebben de beslissingen en inspanningen van het mana- gement belangrijke gevolgen voor de lange termijn. Het gevolg is dat het niet verstandig is om managers van zulke business units uitsluitend 'af te rekenen' op de behaalde financiële resultaten. Doet het hoofdkantoor dat wel. dan zullen de managers van zulke business units te veel belang hechten aan goede resultaten op korte termijn met verwaarlozing van de lange termijn. In concreto kan dat betekenen dat business-unitmanagers minder geld gaan uitgeven voor fundamenteel onderzoek, voor productimnovatie. voor scholing en opleiding van medewerkers, voor het opbouwen en onderhouden van een merknaam of voor preventief onderhoud van installaties dan uit een langetermijnperspectief wenselijk zou zijin. Voor business units met een lange tijdshorizon is dus een linanciële besturingsstijl minder geschikt.

Bij business units met een korte tijdshorizon hebben de beslissingen en inspanningen van business-unitmanagers niet veel gevolgen voor de lange termijn. In die gevallen vormen de behaalde financiële resultaten goede indicatoren voor de prestaties van business-unitmanagers. Het hoofdkantoor kan dan beoordeling en beloning direct koppelen aan de belaalde financiële resultaten. Een beoordeling waarbij ook andere indicatoren worden gebruikt leidt alleen maar tot verzwakking van de prestatieprikkels. Voor business units met een korte tijdshorizon is daarom de strategische besturingsstijl minder geschikt.

\section{De fit tussen besturingsstijl en kenmerken van de portfolio}

Het voorgaande kan als volgt worden samengevat. Om concernvoordelen te kunnen realiseren moet er sprake zijn van een fït tussen de kenmerken van enerzijds de portfolio (de mate van verwantschap van de business units en de tijdshorizon van individuele business units) en anderzijds de besturingsstijl. Maar een dergelijke fit kan niet altijd worden gerealiseerd. Uit figuur 2 blijkt in welke situaties dat het geval is

Als alle business units van een bepaald concern onderling sterk verwant zijn en ook alle een lange tijdshorizon hebben (cel 1 in figuur 2) is een goede fit tussen besturingsstijl en kenmerken van de portiolio mogelijk. Beide kenmerken van de portfolio vragen dan om een strategische besturingsstijl. DSM is daarvan een mooi voor- 


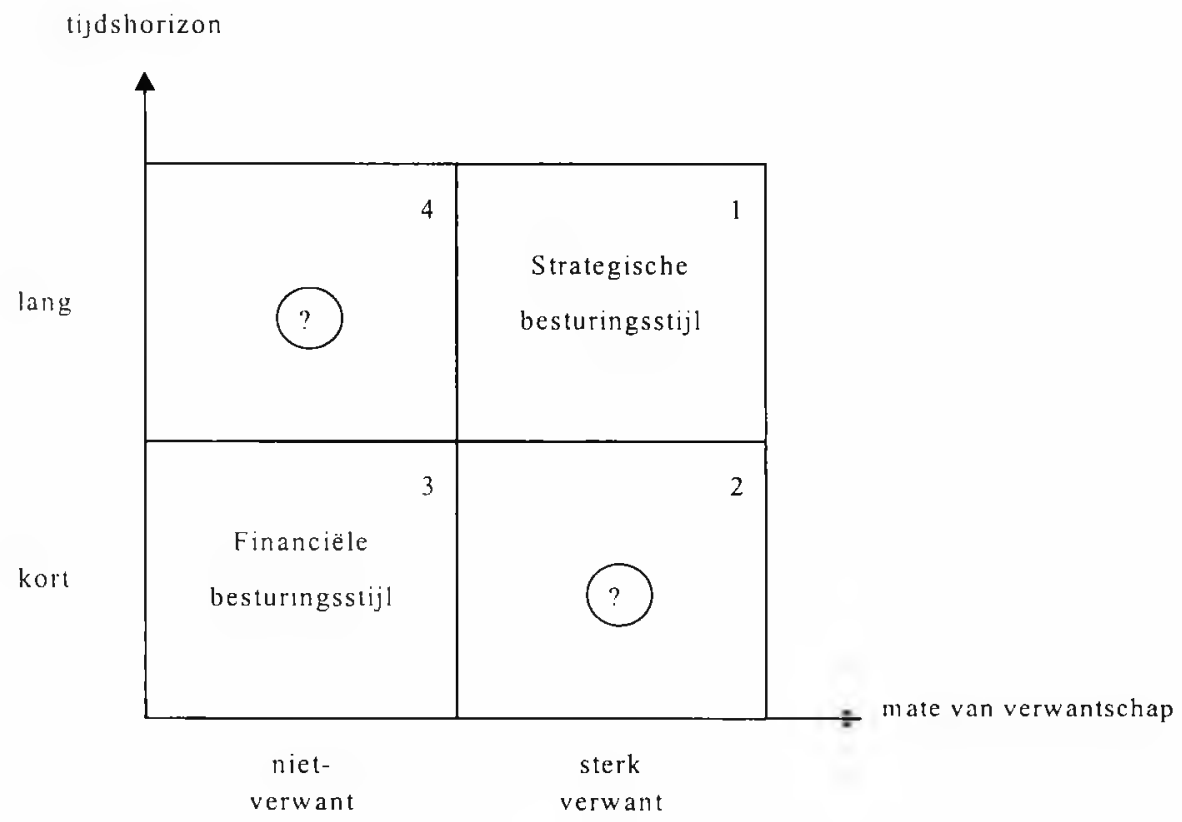

Figun 2: Kenmerken van de portfolio en de hesturingsstijl

beeld: de business units van DSM zijn onderling sterk verwant (er is sprake van onderlinge leveringen. en er is een groot centraal researchlaboratorium) en de business units hebben ook een lange tijdshorizon (research en productinnovatie zijn van groot belang). Door middel van strategische besturing worden synergievoordelen gerealiseerd.

Als de business units van een bepaald concern onderling geen verwantschap vertonen en bovendien alle een korte tijdshorizon hebben (cel 3 in figuur 2), wordt een goede fit bereikt door een financiële besturingsstijl te kiezen.

In figuur 2 komen echter ook twee situaties naar voren waarin een goede fit niet kan worden bereikt. Dat is het geval als de business units een korte tijdshorizon hebben en onderling een sterke verwantschap vertonen (cel 2: vanwege de korte tijdshorizon is een financiële besturingsstijl de aangewezen stijl. vanwege de grote mate van verwantschap lijkt een strategische besturing meer op zijn plaats) en als de business units een lange tijdshorizon hebben en onderling geen enkele verwantschap vertonen (cel 4: vanwege het ontbreken van verwantschap zou het hoofdkantoor een linanciële besturingsstijl moeten toepassen, maar vanwege de lange tijdshorizon zou een strategische besturingsstijl moeten worden gebruikt).
In figuur 2 wordt impliciet verondersteld dat de portfolio met betrekking tot beide kenmerken homogeen is. Zo is verondersteld dat alle business units een korte of alle business units een lange tijdshorizon hebben. Dat behoeft natuurlijk helemaal niet het geval te zijn. Het kan heel goed voorkomen dat sommige business units een korte en andere business units een lange tijdshorizon hebben. Sommige business units vragen dan om een strategische besturingsstijl, andere om een financiële besturingsstiji.

Ook met betrekking tot verwantschap behoeft de portfolio niet homogeen te zijn. Er kan sprake zijn van twee (of meer) groepen van business units, waarbij voor ten minste één van deze groepen geldt dat de business units van die groep onderling een sterke mate van verwantschap vertonen. terwijl tussen de groepen geen verwantschap bestaat. Ten minste één groep van business units vraagt dan om een strategische besturingsstijl, terwijl voor het concern als geheel een financiële besturingsstijl meer geëigend is.

Daarmee zijn in deze paragraaf vier situaties geïdentificeerd waarin een goede fit tussen besturingsstijl en kenmerken van de portfolio niet kan worden bereikt:

a de portfolio bestaat uit sterk verwante business units met een korte tijdshorizon; 
b de portfolio bestaat uit niet-verwante business units met een lange tijdshorizon;

c sommige business units hebben een korte, andere een lange tijdshorizon;

d sommige business units zijn sterk verwant, maar niet verwant aan andere business units.

\section{Besturingsstijl, verwantschap en aantal business units}

Tot dusver zijn slechts twee kenmerken van de portfolio besproken: de tijdshorizon van de business units en de mate van verwantschap lussen de business units. Daarbij is aangegeven dat de kosten van het hoofdkantoor worden beïnvloed door de besturingsstijl (die op zich weer samenhangt met de mate van verwantschap van de business units). De kosten van het hoofdkantoor worden echter ook beïnvloed door het aantal business units. Dat geldt ook voor de te realiseren voordelen (synergievoordelen of financiële voordelen). Dat leidt tot de vraag of er sprake is van een optimum met betrekking tot het aantal business units.

Als de business units een sterke verwantschap vertonen en het hoofdkantoor een strategische besturingsstijl toepast, moet het hoofdkantoor niet alleen aandacht besteden aan iedere business unit afzonderlijk, maar ook aan de relaties tussen de business units. Als het aantal business units gelijk is aan $\mathrm{N}$, zijn er in totaal $1 / 2 \mathrm{~N}(\mathrm{~N}-1)$ relaties tussen de business units. Het lijkt daarom redelijk om te veronderstellen dat de kosten van het hoofdkantoor, bij een strategische besturingsstijl, toenemen met $\mathrm{N}^{2}$. De te realiseren synergievoordelen zullen echter ten hoogste lineair toenemen met N. Zou men alle relevante parameters kennen, dan zou men het concernvoordeel (synergievoordelen verminderd met de kosten van het hoofdkantoor) kunnen uitdrukken in N. Men vindt dan volgens deze redenering een functie van de vorm: $-\mathrm{aN}^{2}+\mathrm{bN}$ (Jones en Hill, 1988). Deze functie heeft een maximum voor $\mathrm{N}=\mathrm{b} / 2 \mathrm{a}$. Daarmee is aannemelijk gemaakt dat er, als alle business units aan elkaar verwant zijn, een optimum met betrekking tot het aantal business units bestaat, ook al is het in de praktijk natuurlijk vrijwel ondoenlijk om dit optimum te berekenen. Als voor een gegeven concern het aantal business units (aanzienlijk) groter is dan dit optimum, kan splitsing van het concern voordelen bieden. Men kan natuurlijk het aantal business units ook verminderen door verkoop of sluiting van een aantal business units. Markides (1995) komt na uitgebreid onderzoek tot de conclusie dat te sterk gediversifieerde ondernemingen ("overdiversified firms") door het afstoten van business units in het algemeen hun winstgevendheid wisten te verbeteren. Het onderzoek van Markides bevestigt dat er een optimale diversificatiegraad bestaat (waarbij het begrip diversificatiegraad wordt gedefinieerd aan de hand van het aantal business units, de grootteverdeling van die business units en de mate van verwantschap tussen de business units). Als die optimale diversificatiegraad overschreden is, is verminderen van de diversificatiegraad (door splitsing van het concern of door verkoop van business units) geboden.

Als de business units geen enkele verwantschap vertonen en het hoofdkantoor een financiële besturingsstijl toepast, behoeft het hoofdkantoor geen aandacht te besteden aan de relaties tussen de business units. Zowel de kosten van het hoofdkantoor als te realiseren voordelen (in dit geval financiële voordelen) zijn lineaire functies van $\mathrm{N}$. Er is dan geen sprake van een optimum met betrekking tot $\mathrm{N}$.

\section{Twee praktijkvoorbeelden}

\section{ATAG Holding $N V$. Zoals elders in dit} nummer uitvoeriger wordt uiteengezet, bestond ATAG Holding in 1997 uit twee groepen van business units, een home products group (verschillende bedrijven in Nederland en Duitsland op het gebied van keukenapparatuur en verwarmingsapparatuur) en een cycle group (verschillende bedrijven in Nederland, Duitsland en Frankrijk op het gebied van fietsen). De bedrijven binnen elk van deze twee groepen vertoonden een duidelijke verwantschap, maar tussen de twee groepen was er geen sprake meer van verwantschap (eerder was er wel sprake geweest van duidelijke verwantschap, zie Manschot en Douma in dit themanummer). Voor ieder van de twee groepen afzonderlijk was een strategische besturingsstijl het meest geschikt. Door het invoeren van een divisiestructuur, met twee in grote mate zelfstandige divisies en het splitsen van het hoofdkantoor van ATAG Holding in twee divisiehoofdkantoren, kon dat ook goed worden gereali- 
seerd. Volgens de hiervoor beschreven gedachtegang zou ATAG Holding nu ten opzichte van haar twee divisies, vanwege het ontbreken van verwantschap een financiële besturingsstijl hebben moeten toepassen, maar vanwege de lange tijdshorizon van elk van de divisies (productinnovatie en merknamen spelen voor beide groepen een grote rol) een strategische besturingsstijl. Dit komt overeen met cel 4 in figuur 2 (pagina 241), waarin een goede fit tussen besturingsstijl en kenmerken van de portfolio niet kan worden bereikt. Nadat bij ATAG de interne verzelfstandiging van de twee divisies had plaatsgevonden en nadat het concernhoofdkantoor was gesplitst in twee divisiehoofdkantoren, was de rol van de holding uiterst beperkt. Als voorbereiding op de splitsing heeft dat goed gefunctioneerd, een permanente oplossing is het niet.

\section{Koninklijke PTT Nederland NV (KPN). KPN} is in 1989 opgericht als voortzetting van het Staatsbedrijf der PTT, dat twee grote operationele hoofddirecties kende: post en telecom. Bij de oprichting van KPN werd besloten beide activiteiten post en telecom niet te splitsen, maar in één vennootschap onder te brengen. KPN had vanaf de start twee zeer grote en belangrijke dochterondernemingen: PTT Post en PTT Telecom. Deze twee bedrijven hadden weinig verwantschap. Vanwege het ontbreken van verwantschap zou het hoofdkantoor een financiële besturingsstijl hebben moeten toepassen, maar vanwege de lange tijdshorizon (in elk geval van PTT Telecom, waarschijnlijk ook van PTT Post) zou het hoofdkantoor een strategische besturingsstijl hebben moeten toepassen. Dit komt ook (net als hierboven) overeen met cel 4 in figuur 2 (pagina 241), waarin een goede fit tussen besturingsstijl en kenmerken van de portfolio niet kan worden bereikt.

\section{Slot}

In dit artikel geven wij antwoord op de vraag in welke situaties het splitsen van een concern voordelen kan bieden. Op die vraag hebben wij twee antwoorden gegeven, die elkaar niet tegenspreken, maar aanvullen.

Het eerste antwoord is dat er situaties zijn waarin een goede fit tussen kenmerken van de portfolio en besturingsstijl niet kan worden bereikt. Vier van die situaties zijn kort samenge- vat aan het slot van paragraaf 4 . Een concern kan terechtkomen in een situatie waarin een goede fit niet kan worden bereikt doordat omstandigheden in de loop van de tijd zijn veranderd (bijvoorbeeld: wat in 1985 sterk verwant was, hoeft in 1999 niet meer verwant te zijn). Splitsen van het concern kan dan een oplossing bieden.

Het tweede antwoord is dat voor concerns die een strategische besturingsstijl toepassen (en een portfolio hebben waarvan de business units onderling sterk verwant zijn en een lange tijdshorizon), de besturingskosten toenemen met het kwadraat van het aantal business units terwijl de mogelijke synergievoordelen lineair toenemen. Als het aantal business units te groot is geworden, kan splitsing van het concern voordelen bieden.

Wij hebben in dit artikel de nadruk gelegd op de besturingsstijl en de besturingskosten in samenhang met de mogelijke synergievoordelen. Wij willen daarmee echter niet pretenderen dat met deze redenering alle gevallen van splitsen van concerns te verklaren zijn. Het Amerikaanse AT\&T splitste zich in 1996 in Lucent Technologies, NCR Corp. en AT\&T. Voor de splitsing was AT\&T verticaal geïntegreerd. Het produceerde hardware en was tegelijkertijd telefoonmaatschappij. Andere telefoonmaatschappijen begonnen echter de voorkeur te geven aan andere leveranciers, omdat ze niet langer apparatuur wilden kopen van een concurrent. Met dit voorbeeld willen we aangeven dat onze redenering wel veel, maar niet alle splitsingen kan verklaren.

\section{I T E R A T U U R}

Goold, M. en A. Campbell, (1987), Strategies and styles: the role of the centre in managing diversified corporations. Oxford/New York, Basil Blackwell.

Hill, C.W.L., (1988), Internal capital market controls and financial performance in multidivisional firms, Journal of Industrial Economics, jrg. 37, pp. 67-83.

Hill, C.W.L., (1994), Diversification and economic performance: bringing structure and corporate management back into the picture, in: R.O. Rumelt, D.E. Schendel en D.J. Teece (red.), Fundamental issues in strategy: a research agenda, Boston, Harvard Business School Press.

Hill, C.W.L. en R.E. Hoskisson, (1987), Strategy and structure in the multiproduct firm, Academy of Management Review. jrg. 12, pp. 331-341. 
Hoskisson, R.E., (1987), Multidivisional structure and performance: the contingency of diversification strategy, Academy of Management Journal, jrg. 30, pp. 625-644.

Jones, G.R. en C.W.L. Hill, (1988), Transaction cost analysis of strategy-structure choice, Strategic Management Journal, jrg. 9, pp. 159-172.

Markides, C.C., (1995), Diversification, restructuring and economic performance, Strategic Management Journal, jrg. 16, pp. 101-118.

Oijen, A.A.C.J. van, (1997), Besturing door het hoofdkantoor en diversificatie, proefschrift Katholieke Universiteit Brabant.

Ramanujam, V. en P. Varadarajan, (1989), Research on corporate diversification: a synthesis, Strategic Management Journal, jrg. 10, pp. 523-551.

\section{NOOT}

1 Goold en Campbell onderscheiden drie besturingsstijlen die zij aanduiden als 'strategic planning', 'strategic control' en 'financial control'. Daarbij komt 'strategic planning' grotendeels overeen met wat wij de strategische besturingsstijl hebben genoemd en 'financial planning' overwegend met wat wij de financiële besturingsstijl hebben genoemd. 'Strategic control' kan als een tussenvorm tussen die twee worden beschouwd. 